\title{
Tips for Facilitating Morning Report
}

Luke A. Devine, Wayne L. Gold, Andrea V. Page, Steven L. Shumak, Brian M. Wong, Natalie Wong, Lynfa Stroud

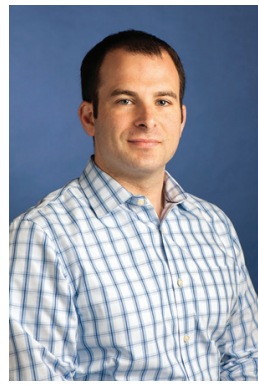

Luke A. Devine

\begin{abstract}
About the Authors: Luke Devine is an assistant professor in the Division of General Internal Medicine at the University of Toronto. He is the internal medicine clerkship site co-director at Mount Sinai Hospital and the simulation lead at the HoPingKong Centre - CEEP, University Health Network, Toronto. Wayne L. Gold is a professor of medicine in the Divisions of Infectious Diseases and General Internal Medicine and program director for the Adult Infectious Diseases Program at the University of Toronto. Andrea V. Page is an assistant professor in the Division of Infectious Diseases, University of Toronto, and postgraduate site director for the Internal Medicine Training Program at Mount Sinai Hospital, Toronto. Steven L. Shumak is a professor of medicine, Department of Medicine at the University of Toronto and is a general internist at Sunnybrook Health Sciences Centre. Brian Wong is an associate professor in the Division of General Internal Medicine, Department of Medicine, and associate director of the Centre for Quality Improvement and Patient Safety. Natalie Wong is an assistant professor of internal medicine and critical care, in the Department of Medicine and postgraduate site director for the Internal Medicine Training Program at St. Michael's Hospital, Toronto. Lynfa Stroud is an assistant professor of internal medicine, in the Department of Medicine and postgraduate site director for the Internal Medicine Training Program at Sunnybrook Health Sciences Centre, Toronto. Correspondence may be directed toldevine@mtsinai.on.ca.
\end{abstract}

\begin{abstract}
Morning report (MR) is a valued educational experience in internal medicine training programs. Many senior residents and faculty have not received formal training in how to effectively facilitate MR. Faculty at the University of Toronto were surveyed to provide insights into what they felt were key elements for the successful facilitation of MR. These insights fell within 5 major categories: planning and preparation, the case, running the show, wrapping up and closing the loop.
\end{abstract}

\section{Résumé}

Le rapport du matin (RM) est un outil pédagogique précieux dans les programmes de formation en médecine interne. Nombre de résidents séniors et de membres du corps enseignant nont toutefois jamais reçu de formation officielle sur la façon de faciliter l'élaboration du RM. Nous avons sondé les membres du corps enseignant de l'université de Toronto pour avoir un aperçu de ce qu'ils percevaient comme étant des éléments-clés susceptibles d'améliorer grandement lélaboration du RM. Les réponses reçues se répartissent en cinq principales catégories: la planification et la préparation du RM, les caractéristiques du cas évalué, l'importance et la façon de prendre en main le processus, le résumé des informations et l'art de «boucler la boucle ».

Morning report (MR) has long been an integral and valued part of Internal Medicine training programs in North America. ${ }^{1,2}$ Some residents recognize MR as the most important educational activity during their training. ${ }^{3}$ Medical students, residents and faculty typically attend MR. Although the structure and function of MR can vary across institutions, it usually involves a case-based discussion facilitated by a faculty member, chief medical resident (CMR), or other senior resident. The facilitator discusses pertinent aspects of one or more clinical cases to teach medical knowledge, clinical reasoning and other important aspects of physician competencies, such as communication and collaboration skills. ${ }^{4}$ Residents have expressed a preference for an interactive teaching session led by an individual with extensive medical knowledge and excellent clinical acumen. ${ }^{5}$

Despite trainees' perceptions about the core educational function of MR and their preference for skilled facilitators, most residents and many faculty have never received any formal training on how to conduct an effective MR. This, coupled with a lack of resources in the literature, may contribute to feelings of trepidation about assuming the role of facilitator. ${ }^{6}$ Based on this 
need, we were invited by the organizing group of residents at the 2015 Canadian CMR Conference, held in Toronto, Canada, to lead a seminar to introduce CMRs to the principles of effective MR facilitation. The conference was attended by over 70 current and future CMRs. In preparation for this seminar, we reviewed available literature and found that practical guidelines on how to facilitate a successful MR were generally lacking. To help us to provide guidance and to capture broad opinions and experiences, we recruited a sample of 24 faculty at the University of Toronto, including many award-winning teachers whose experience in leading MR ranges from 3 to over 30 years. We asked them to provide insights into what they felt were key elements of facilitating a successful MR. While not a systematic collection of data, their insights taken together represent a broad experience base. Given the relative lack of evidence-based literature describing how to facilitate MR, we decided to disseminate a refined summary of the shared wisdom we uncovered in hopes that it would benefit other CMRs and junior faculty as they take on this challenging role.

The insights provided fall within 5 main themes (Table 1) which are discussed below, followed by a brief discussion about future directions for MR:
1. Planning and preparation
2. The case
3. Running the show
4. Wrapping up
5. Closing the Loop

Table 1. Experience-Based Tips to Running an Effective Morning Report

\section{PLANNING AND PREPARATION:}

1) Ensure audiovisual aids are present and working before starting.

2) Start and end on time.

3) Encourage all faculty to attend and participate.

4) Know the audience (including names).

\section{THE CASE:}

5) The case can be undifferentiated or one for which the diagnosis and even response to treatment are known.

6) There are pros and cons to the facilitator knowing details of the case in advance.

7) If details of the case are not known to the facilitator, determine with the person presenting if the discussion should be focused on diagnosis, management or other pertinent issues.

8) Cases need not be limited to inpatients and can include ambulatory cases and case simulations.

\section{RUNNING THE SHOW:}

9) Establish a respectful learning climate.

10) Personal anecdotes and reflections on past cases can engage the audience.
11) Ensure time is spent discussing learning issues valuable to all present.

12) Facilitate and engage in discussion rather than deliver a lecture.

13) Use a mix of pattern recognition (heuristics) and analytical reasoning strategies.

14) Start with a question that has an obvious answer if dealing with a quiet audience.

15) Promote volunteerism for answers as much as possible, but direct a question to a specific person if no one volunteers.

16) Begin by engaging the most junior learners and advance to involve senior learners.

17) Encourage resource stewardship and evidence-based medicine.

18) Acknowledge areas of uncertainty and don't be afraid to say "I don't know".

19) Teaching "scripts" or the use of a systematic approach to developing a differential diagnosis can be used when discussing less familiar topics.

20) Highlight the variability in clinical approach amongst "the experts" in the room.

\section{WRAPPING-UP:}

21) Ensure there is time to summarize "take home points".

22) Provide learners with the opportunity to summarize what they have learned.

\section{CLOSING THE LOOP:}

23) Reinforcement of learning can include a distribution of a relevant paper or providing a summary of learning points via email or blog.

24) Maintain a case log to ensure a balanced curriculum.

25) Provide feedback to the case presenter and facilitator.

\section{Planning and Preparation}

It is important for the organizer and facilitator (these may or may not be the same person) to be diligent when preparing for MR. The person in charge of organizing MR should ensure that all necessary audiovisual equipment is in working order, which may be as simple as ensuring there is a whiteboard and working marker. To optimize housestaff attendance, the sessions and facilitators should be scheduled in a regular and predictable way. The lure of a light breakfast should not be underestimated and may add to the social aspect of this event. Sessions should begin and finish on time (or even slightly early). Ideally, deferring pages for all but critical clinical issues should occur. Having faculty regularly attend MR as audience participants, and not just as facilitators, improves the attendance of learners who see through role-modelling the importance of continuing medical education and lifelong learning. Faculty presence also raises the level of discussion around grey areas of diagnosis and management, providing trainees with a spectrum of opinions and approaches 
to clinical medicine, specifically role-modelling how faculty approach clinical uncertainty. The organizer must also ensure that someone, usually a trainee, is responsible for bringing the details of one or more clinical cases to be discussed.

The facilitator should ensure they know the names and year of training of the housestaff in attendance. It is helpful if the organizer can provide a list (ideally with pictures) of those who will be in attendance for the facilitator to reference. Over time, this helps to develop a sense of community within the group. It also allows the facilitator to engage all participants, with the goal of first posing level-specific questions to the more junior learners and ending with the most senior learners.

\section{The Case}

The selected clinical case can be either a new patient seen in consultation in the past 24 hours or a patient that has been in hospital for some time and for whom results of investigations and response to treatment are known. Ideally, the majority of the cases selected should not involve particularly rare medical issues and should mirror the clinical case mix of patients being cared for by the trainees. Trainees will benefit more from discussions about common clinical problems. However, to highlight issues of diagnostic reasoning, it can be beneficial to occasionally discuss uncommon cases including typical presentations of rare diseases or unusual presentations of common problems.

The faculty surveyed expressed differing opinions when asked if they thought the details of the case should be known to the facilitator in advance. Knowing the details of the case in advance can ensure the facilitator is comfortable with the content area and allows them to focus on aspects of the case that they think will have the highest learning impact for trainees. However, when the case is not known to the facilitator, the audience will be more likely to garner insight into the clinical reasoning process of the facilitator. The opportunity to learn about the cognitive process that an "expert" uses when generating a differential diagnosis and formulating plans for investigation and management is potentially much more valuable than the discussion of content that could be read in a textbook or electronically. When the details of a case are not known, the discussion is more spontaneous and the lines of discussion are more reflective of the thoughts of the trainees, rather than the facilitator. The discussion can be guided by the case itself and the trainees' questions and answers. A mixed approach to case discussion will provide the variety that the participants value.

Although traditionally MR has focused on the diagnosis or management of one or more clinical cases from the inpatient service, its format is flexible enough to provide opportunity for discussion of other important aspects of patient care. MR can also address ambulatory cases, ${ }^{7}$ include the presence of a real patient for the purposes of highlighting history-taking and clinical findings and also incorporate discussion of simulated cases, such as code blue scenarios. The discussion can also be enriched by the health professionals from other disciplines including, pharmacists, physical therapists, occupational therapists, nurses, and social workers. The case can also be selected to allow the discussion to be focused on other specific elements of management, such as resource utilization and "choosing wisely," quality and safety, bioethics, and evidence-based medicine. ${ }^{9}$

\section{Running the Show}

In developing their skills in facilitation, many of the faculty surveyed stated that they continuously build on the facilitation skills that they have learned over time, the basic principles of which are described elsewhere. ${ }^{10,11}$ Through feedback and reflection, they adapt a style that reflects how they believe the MR should be conducted.

The facilitator must establish a respectful climate at MR that is conducive to learning. He or she must ensure that the session is collegial and enforce that the goal of the session is learning, rather than showmanship. The environment should encourage interaction and permit people to ask questions. Trainees should feel comfortable enough to answer questions and test hypotheses, even if answers are incorrect. However, the facilitator must ensure that the correct information is conveyed to the group and that incorrect answers are explored as key teaching points. Humour can put people at ease. Self-deprecating humour can be non-threatening and freely employed if it is within the facilitator's comfort zone. However, humour should never come at the expense of a trainee. Personal anecdotes and reflections on past cases can engage the audience, relax the atmosphere and vividly impart key facts and clinical wisdom.

It is important for the facilitator to be respectful of time. Trainees often report that too much time is spent on reviewing the history and physical examination and on the development of an exhaustive differential diagnosis while less time is spent on investigation and management issues, which senior trainees find most valuable. There need not be a fixed formula related to how much time to spend on specific components of the case. A skilled facilitator will expand and abbreviate aspects of the case discussion based on the specific case presented. Some cases represent excellent opportunities to review evidence-based physical examination, some may highlight issues of resource stewardship related to investigation and some are particularly well-suited to discussion of evidence-based management.

The facilitator should facilitate a clinical discussion, rather than deliver a didactic talk. He or she should coach the participants to identify key historical facts or findings on physical examination to allow everyone to fully participate in the case formulation 
and clinical reasoning that will follow. Demonstrating a mix of pattern recognition and heuristics (e.g., "Quick - what do you think the diagnosis is?") and analytical reasoning strategies will help trainees learn to employ and recognize the strengths and limitations of each.

In the face of a quiet audience, questions that have obvious answers should be posed first. The facilitator should promote volunteerism as much as possible; however, addressing specific members of the audience prevents silence and can help ensure everyone is engaged in the discussion. Sensitivity to the level of trainee is important. A facilitator should avoid potential embarrassment of a trainee by allowing a more junior learner to come up with the answer to a question that the more senior trainee could not answer. In other words, there should be an inviolate sequence wherein, for any given topic, the facilitator starts with trainees at an appropriate level for the questions and moves upward sequentially by level of training. This allows participants to relax and set their focus on learning, rather than avoiding eye contact and fearing embarrassment.

A skilled facilitator should not allow any one person to dominate the discussion and should also refrain from asking multiple questions to the same participant. However, it can be valuable to challenge a respondent or the group to elaborate on their answers, as this can uncover gaps in knowledge and understanding and provide additional opportunities for learning.

It is important to ensure that the discussion is of interest to trainees at all levels. If faculty are present, their opinions should be sought throughout the case. It is helpful to highlight the variability in approach amongst "the experts" in the room. Judicious use and justification of investigations should be encouraged to promote learning about resource stewardship and evidence-based medicine principles should be incorporated, when relevant.

Many facilitators are anxious about how to handle situations where they don't know the answer to a particular clinical problem. In these cases, a demonstration of the clinical reasoning process and a focus on an approach to clinical problems can be helpful. Some of the most useful discussions centre on how to deal with uncertainty and on how to find answers to clinical questions in real-time using available resources. The facilitator should not hesitate to say "I don't know," as this demonstrates that nobody has infinite knowledge and role-models the necessity of recognizing one's limitations. Teaching scripts relating to specific topics or the use of an etiologic or body systems-based approach to developing a differential diagnosis are helpful teaching approaches ${ }^{6}$.

\section{Wrapping Up}

Sufficient time should be dedicated to recapitulation and repetition of 1 to 3 key take home messages. This serves to reinforce the important points that were discussed and to ensure that participants walk away with key messages to facilitate learning. Having a few members of the audience identify what they have learned is often beneficial as the facilitator may not identify the same issues as the trainees.

\section{Closing the Loop}

Further reinforcement can occur if a summary of the take home points or a relevant paper is circulated by email or posted to a blog. ${ }^{12}$ This must be done in a manner that protects patient confidentiality. Updates on previously presented diagnostic dilemmas will enhance learning. Finally, the organizer of MR can keep a log of cases that have been presented to avoid excessive repetition of topics and ensure a balanced curriculum.

A process for the person presenting the case to be provided with feedback about their presentation skills by the facilitator or peers should be implemented. It is also important for the facilitator to receive feedback about their teaching and the session overall. Feedback will help faculty refine their facilitation skills, especially if coupled with faculty development initiatives to improve teaching skills. ${ }^{13}$ It may also be important for novice clinician teachers who need to build a teaching portfolio as part of their academic review and promotion process. ${ }^{14}$ If it is clear the faculty utilize the feedback, it serves to role-model self-reflection and promote a culture of frequent formative feedback.

\section{The Future of MR}

MR has a long tradition and can be an evolving teaching format capable of meeting current educational needs. For example, with the implementation of competency-based medical education (CBME) into residency training programs, the competencies being developed for Internal Medicine trainees can provide a framework to organize aspects of learning experiences, including $\mathrm{MR} .{ }^{15}$ Issues of advocacy and stewardship may be highlighted as explicit learning points of cases, as MR allows for discussion of authentic core clinical tasks and problems, avoiding the reduction of competencies to endless lists taught without the necessary context needed for deeper learning. ${ }^{16}$ There are also challenges to implementing and sustaining a successful MR in today's current training climate. Issues such as duty-hour restrictions, increased volume and acuity of patients, and pressure to discharge patients early in the day ${ }^{17-19}$ have prompted some to modify the traditional MR. An "afternoon report" allows for attention to 
clinical duties early in the day and preserves teaching for later in the day. MR should continue to evolve to meet current education and healthcare delivery needs, and these innovations should be described in the literature and studied.

Although these tips have been generated from shared experiences at a single centre, we believe they will be useful to facilitators in many other settings, as they represent the experiences of many facilitators with many cumulative years of experience. This article is intended to stimulate others to reflect upon and discuss what they have found to be the key elements of facilitating a successful MR.

\section{Acknowledgements}

We would like to thank our colleagues who contributed tips and whose teaching has influenced the careers of countless trainees: Dr. Ahmed Bayoumi, Dr. Isaac Bogoch, Dr. Mark Cheung, Dr. Allan Detsky, Dr. Irfan Dhalla, Dr. Vera Dounaevskaia, Dr. Trevor Jamieson, Dr. Lauren Lapointe Shaw, Dr. Jerome A. Leis, Dr. Don Livingstone, Dr. Julia Lowe, Dr. Ophyr Mourad, Dr. Valerie Palda, Dr. Joel Ray, Dr. Donald Redelmeier, Dr. Steve Shadowitz, Dr. Rob Sargeant.

\section{References}

1. Parrino TA, Villanueva AG. The principles and practice of morning report. JAMA 1986;256(6):730-33.

2. Amin Z, Guajardo J, Wisniewski W, Bordage G, Tekian A, Niederman LG. Morning report: focus and methods over the past three decades. Acad Med 2000;75(10):S1-S5.

3. Gross CP, Donnelly GB, Reisman AB, Sepkowitz KA, Callahan MA. Resident expectations of morning report: a multi-institutional study. Arch Int Med 1999;159(16):1910-14.

4. McNeill M, Ali SK, Banks DE, Mansi IA. Morning report: can an established medical education tradition be validated? J Grad Med Educ 2013;5(3):374-84.
5. Ways M, Kroenke K, Umali J, Buchwald D. Morning report: A survey of resident attitudes. Arch Int Med 1995;155(13):1433-37.

6. Sacher AG, Detsky AS. Taking the stress out of morning report: an analytic approach to the differential diagnosis. J Gen Intern Med 2009;24(6):747-51.

7. Wenderoth S, Pelzman F, Demopoulos B. Ambulatory morning report. J Grad Med Educ 2002;17(3):207-209.

8. Kane GC, Holumzer C, Sorokin R. Utilization management morning report Purpose, planning and early experience in a university hospital residency program. Sem Med Pract 2001;4(1):27-36.

9. Banks DE, Runhua Shi M. Decreased hospital length of stay associated with presentation of cases at morning report with librarian support. J Med Libr Assoc 2007;95(4):381-87.

10. Azer SA. Challenges facing PBL tutors: 12 tips for successful group facilitation. Med Teach 2005;27(8):676-81.

11. Skeff KM. Enhancing teaching effectiveness and vitality in the ambulatory setting. J Gen Intern Med 1988;3(1):S26-S33.

12. Bogoch II, Frost DW, Bridge S, Lee TC, Gold WL, Pansiko DM, Cavalcanti R. Morning report blog: a web-based tool to enhance case-based learning. Teach Learn Med 2012;24(3):238-41.

13. Boerboom TB, Stalmeijer RE, Dolmans DH, Jaarsma DA. How feedback can foster professional growth of teachers in the clinical workplace: A review of the literature. Stud Educ Eval 2015;46:47-52.

14. Fleming VM, Schindler N, Martin GJ, DaRosa DA. Separate and equitable promotion tracks for clinician-educators. JAMA 2005;294(9):1101-1104.

15. Frank JR, Snell LS, Ten Cate O, Holmboe ES, Carraccio C, Swing SR, Harris, KA. Competency-based medical education: theory to practice. Med Teach, 2010;32(8):638-45.

16. Hawkins RE, Welcher CM, Holmboe ES, Kirk LM, Norcini JJ, Simons KB, Skochelak SE. Implementation of competency based medical education: are we addressing the concerns and challenges? Med Educ. 2015;49(11):1086-1102.

17. Arora VM, Georgitis E, Siddique J, Vekhter B, Woodruff JN, Humphrey HJ, Meltzer DO. Association of workload of on-call medical interns with on-call sleep duration, shift duration, and participation in educational activities. JAMA 2008;300(10):1146-53.

18. Horwitz LI, Krumholz HM, Huot SJ, Green ML. Internal medicine residents' clinical and didactic experiences after work hour regulation: a survey of chief residents. J Gen Int Med 2006;21(9):961-65

19. Khanna S, Sier D, Boyle J, Zeitz K. Discharge timeliness and its impact on hospital crowding and emergency department flow performance. Emerg Med Aus 2016;28(2):164-70. 